\title{
Os desafios do acesso aos serviços de Abastecimento de Água e Esgotamento Sanitário ao Norte do Brasil, em tempos de pandemia da Covid-19
}

The challenges of access to Water Supply and Sanitary Sewage services in Northern Brazil, in times of Covid-19 pandemic

\section{Los desafíos del acceso a los servicios de abastecimiento de agua y alcantarillado sanitario en el} norte de Brasil, en tiempos de la pandemia Covid-19

Francisca Nara da Conceição Moreira ORCID: https://orcid.org/0000-0001-5983-5190 Instituto Federal de Educação, Ciência e Tecnologia do Pará, Brasil E-mail: francisca.moreira@ifpa.edu.br Patricia da Silva Chaves ORCID: https://orcid.org/0000-0003-3560-5395
Instituto Federal de Educação, Ciência e Tecnologia do Pará, Brasil E-mail: patricia.chaves@ifpa.edu.br Nellyana Borges dos Santos ORCID: https://orcid.org/0000-0002-1236-8019 Instituto Federal de Educação, Ciência e Tecnologia do Pará, Brasil E-mail: nellyana.borges@ifpa.edu.br Ranilson Alves dos Santos ORCID: https://orcid.org/0000-0003-4445-7830 Instituto Federal de Educação, Ciência e Tecnologia do Pará, Brasil E-mail: ranilson.alves@ifpa.edu.br

\begin{abstract}
Resumo
Os desafios do acesso aos serviços de Abastecimento de Água e Esgotamento Sanitário em tempos de pandemia da Covid-19. A pesquisa foi dividida em 5 etapas. Inicialmente, foi realizado um levantamento de dados bibliográficos. Em seguida, foram definidos os indicadores de saneamento de trabalhados na pesquisa. Na etapa III, foi elaborado o formulário virtual para a coleta de dados. Finalizando, foram discutidos e analisados os dados obtidos. Como resultado dessa pesquisa, foi constatado que nem todos os moradores de CDA possuíam acesso aos serviços básicos de abastecimento de água e esgotamento sanitário. Além disso, em 13,5\% dos domicílios ocorria falta de água pelo menos uma vez por semana. Também, $73,7 \%$ das residências não tinham acesso à rede coletora de esgoto. Em $24,4 \%$ utilizava-se fossa negra para disposição do esgoto gerado. Diante desse cenário, é renovada a importância de planejamento e investimentos em estruturas básicas de saneamento tanto nas capitais quanto nos municípios do interior do Estado do Pará, pois entende-se que dessa forma será possível reduzir não só o contágio da COVID-19, mas, também, de tantas outras doenças ocasionadas pela ausência de serviços básicos de saneamento.
\end{abstract}

Palavras-chave: Água; Esgoto; Covid-19; CDA.

\begin{abstract}
The Challenges of Accessing Water Supply and Sanitation Services in Times of Covid-19 Pandemic. The research was divided into 5 steps. Initially, bibliographic data survey was carried out. Then, the sanitation indicators worked on in the research were defined. In step III, the virtual form for data collection was created. Finally, the obtained data were discussed and analyzed. As a result of this research, it was found that not all CDA residents had access to basic water supply and sanitation services. Furthermore, in $13.5 \%$ of households there was a lack of water at least once a week. Also, $73.7 \%$ of homes did not have access to a sewage collection network. And $24.4 \%$ used a black cesspool to dispose of the generated sewage. In this scenario, the importance of planning and investing in basic sanitation structures is renewed both in the capitals and in the municipalities in the interior of the State of Pará. Because, it is understood that this way it will be possible to reduce not only the contagion of COVID-19, but also of so many other diseases caused by the absence of basic sanitation services.
\end{abstract}

Keywords: Water; Sewer; Covid-19; CDA.

\section{Resumen}

Los desafíos del acceso a los servicios de abastecimiento de agua y saneamiento en tiempos de la pandemia Covid-19. La investigación se dividió en 5 pasos. Inicialmente se realizó un levantamiento de datos bibliográficos. Luego, se 
definieron los indicadores de saneamiento trabajados en la investigación. En el paso III, se creó el formulario virtual para la recolección de datos. Finalmente, se discutieron y analizaron los datos obtenidos. Como resultado de esta investigación, se encontró que no todos los residentes de CDA tenían acceso a servicios básicos de abastecimiento de agua y saneamiento. Además, en el $13,5 \%$ de los hogares faltaba agua al menos una vez a la semana. Además, el $73,7 \%$ de los hogares no tenía acceso a un sistema de recolección de aguas residuales. Y el 24,4\% utilizó un pozo negro para eliminar las aguas residuales generadas. En este escenario, se renueva la importancia de la planificación e inversiones en estructuras de saneamiento básico tanto en las capitales como en los municipios del interior del Estado de Pará, pues se entiende que de esta manera se podrá reducir no solo la contagio de COVID-19, pero también de tantas otras enfermedades provocadas por la ausencia de servicios básicos de saneamiento.

Palabras clave: Agua; Alcantarilla; Covid-19; CDA.

\section{Introdução}

Atualizada pelo marco legal, a garantia da prestação dos serviços de saneamento básico são itens essenciais para a saúde da população. Neste sentido, o poder público tem se esforçado para ampliar esses serviços nos últimos anos a fim de garantir o acesso da população, de acordo com os critérios atualizados na lei $n^{\circ} 14.026 / 2020$, a qual estabelece diretrizes nacionais para o saneamento básico.

Corroborando com Wang (2020) e Zhu et al. (2019), os serviços de saneamento básico, em especial, a ampliação da cobertura do fornecimento de água potável, o sistema de esgotamento sanitário e condições de higiene são essenciais na proteção da saúde humana nos períodos de surtos de doenças infecciosas, tal como causado pelo novo coronavírus.

O acesso ou não ao saneamento básico tem influência direta na qualidade de vida da população, no desenvolvimento da sociedade e na proteção do meio ambiente. Nesse sentido, Yinyin et al. (2016) e Chernicharo (2018) comentam que a provisão de condições de saneamento adequadas são fatores essenciais para a segurança, proteção e saúde da população.

A Organização das Nações Unidas (ONU) (2010) declarou os serviços de abastecimento de água e esgotamento sanitário como direito fundamental e instrumento para promoção da saúde, principalmente às populações mais vulneráveis. Para Zhang (2016) e Wang (2020), o fornecimento de água potável, a coleta e tratamento de esgoto e condições de higiene são fundamentais para proteger a saúde em todos os surtos de doenças infecciosas.

A respeito disso, Xiao (2020) e WU et al. (2020) explicam que o acesso a esses serviços (abastecimento de água e esgotamento sanitário) foram ainda mais necessários com a chegada do SARS-CoV-2 ao mundo. A pandemia reforçou para mais a importância do acesso aos serviços de saneamento básico e as práticas comuns de higiene.

As principais ações recomendadas estão na higienização frequente e adequada das mãos e uso de máscaras, que se aliaram como medidas cruciais para prevenir a infecção pelo coronavírus; e tem sido uma das principais mensagens para reduzir a propagação da doença no mundo. Todavia, isso requer o acesso contínuo aos serviços de abastecimento de água e esgotamento sanitário, sobretudo para higienização nos domicílios, estabelecimentos de saúde, locais de trabalho, escolas e espaços públicos, etc.

De acordo com a Pesquisa Nacional por Amostra de Domicílios Contínua (PNAD) (2019), aproximadamente 10,5 milhões de domicílios brasileiros (14,5\%) não contavam com acesso à rede de distribuição de água tratada como principal fonte de abastecimento. Além disso, na PNAD (2019) é observado, ainda, que o acesso ao esgotamento sanitário é insuficiente; e quase um terço dos domicílios não estão ligados à rede geral de esgotamento sanitário. Diante dessa situação, a prevenção ao COVID-19 deve ser pensada de forma sistêmica, uma vez que grande parcela da população não tem acesso à água de qualidade e menos ainda a coleta e tratamento de esgoto; dados do Sistema Nacional de Informações sobre Saneamento (SNIS) mostram esses cenários.

Diante desse quadro, o meio adequado ao abastecimento de água e esgotamento sanitário aliados às medidas de higiene são itens indispensáveis na prevenção contra o COVID-19; bem como o monitoramento do esgoto sanitário tem somado forças juntos aos mecanismos de vigilância em saúde em todos os órgãos competentes no mundo. 
No contexto atual de pandemia, o trabalho parte do princípio de que, também, o levantamento de informações sobre o acesso populacional aos serviços de abastecimento de água e esgotamento sanitário é de fundamental importância. Além disso, certamente é um aliado crucial no planejamento de ações para combater o coronavírus Covid-19, e contribuir com os órgãos governamentais competentes no planejamento de ações, sendo esse o objetivo da pesquisa em questão.

\section{Metodologia}

A presente pesquisa foi desenvolvida na cidade de Conceição do Araguaia (CDA), localizada no sudeste paraense, ao norte brasileiro, nas coordenadas geográficas $8^{\circ} 15^{\prime} 47.2^{\prime \prime} \mathrm{S} 49^{\circ} 16^{\prime} 08.9^{\prime \prime} \mathrm{W}$. Está situada às margens do Rio Araguaia que divide o estado do Pará com Tocantins, conforme mostrado na Figura 1. O estudo tem caráter quantitativo e qualitativa, sendo realizado por meio de levantamento bibliográfico e formulário online para coleta dados (ESTRELA, 2018). Para tanto, a pesquisa foi dividida em 4 etapas de atividades.

Figura 1. Localização da Cidade de Conceição do Araguaia, Pará.

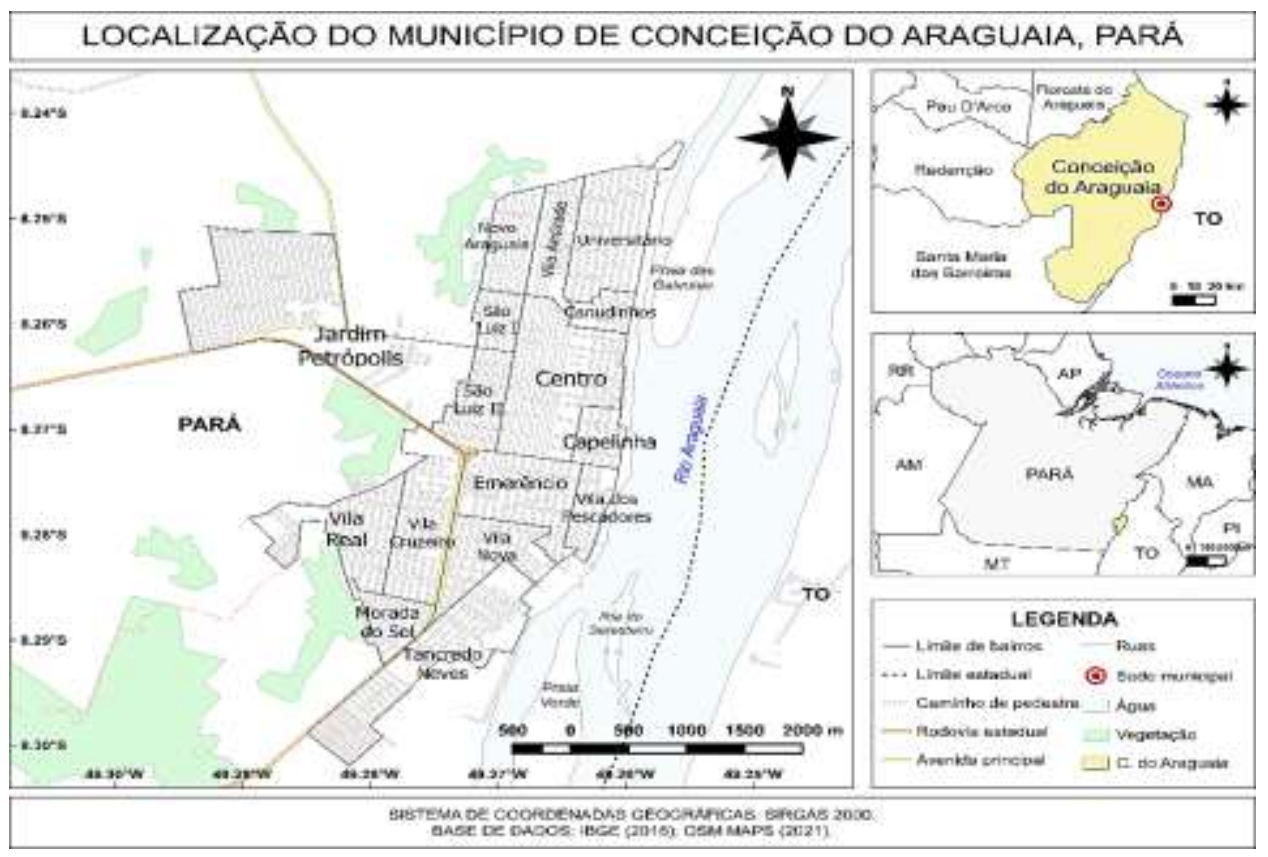

Fonte: Autores.

No primeiro momento ocorreu a revisão bibliográfica caracterizada como analítica, consultando periódicos científicos, fontes governamentais, dentre outros. Essa etapa foi de grande relevância, pois possibilitou compreender, em parte, a relação entre sistema de abastecimento de água, esgotamento sanitário e COVID-19, para a finalidade de subsidiar o cumprimento dos objetivos desse trabalho.

Em seguida, ocorreu a seleção dos indicadores para melhor entendimento do acesso populacional. Para tanto, foram designados indicadores da base de dados do SNIS para conhecimento e avaliação dos serviços de abastecimento de água e esgotamento sanitário em CDA, sendo selecionados para esgotamento sanitário: o índice de coleta de esgoto, o índice de tratamento de esgoto e o índice de atendimento total de esgoto; e para o abastecimento de água foi nomeado o índice de atendimento total de água.

Posteriormente, os dados foram obtidos por meio de questionário eletrônico estruturado, elaborado no Google Forms $\circledR$ com a maioria das questões fechadas, a fim de que fosse possível a transformação de uma série de fatos qualitativos 
(denominados atributos) numa série de valores quantitativos (denominados variáveis). Permitiu-se, assim, a análise estatística dos dados, conforme esclarecido por Canziani (2001).

Em decorrência do cenário de pandemia, optou-se em não direcionar a participação pessoal de moradores a um determinado bairro. Por isso, o formulário foi distribuído por diversos grupos de Whatsapp®, e ficaram disponíveis para o preenchimento por 15 dias, evitando qualquer tipo de contato e contágio.

Para a tabulação dos questionários, foi utilizada a planilha eletrônica Excel®, gerada automaticamente a partir dos dados do Google Forms ${ }^{\circledR}$, sendo que em muitas situações o aplicativo já disponibiliza também os gráficos. Ao finalizar, foi possível descrever e discutir os resultados sobre o contexto atual do acesso da população de Conceição do Araguaia aos serviços de abastecimento de água e esgotamento sanitário.

\section{Resultados e Discussão}

\subsection{Análise e discussão dos resultados da intervenção}

A pesquisa teve a participação de 156 moradores de diferentes bairros de CDA; foi verificada maior participação do Bairro Centro com 19,2\% e a Bairro Vila Cruzeiro com 16,7\% participantes. Vale comentar que os questionários não foram direcionados a bairros específicos, pois considerando a necessidade de se manter o distanciamento social ficaria inviável a aplicação do questionário de forma presencial. Diante disso, optou-se pelo formulário eletrônico.

\subsection{Presença de doenças ocorridas com os participantes}

Diversas localidades no mundo sofrem com a ausência de saneamento básico, e no Brasil não é diferente; a ausência desses serviços têm como consequências riscos à saúde da população e da qualidade do meio ambiente. Os participantes da pesquisa foram questionados sobre os tipos de enfermidades adquiridas ou não na cidade de Conceição do Araguaia, no Pará.

Nesse contexto, foi observado que $0,6 \%$ dos entrevistados contraíram dengue e malária. A dengue é uma doença viral transmitida pela picada do mosquito do gênero Aedes, que tem maior ocorrência em época chuvosa. Em 2020, foram verificados aumento de casos em todo território brasileiro, segundo Ministério da Saúde. A principal medida de prevenção é eliminar os criadouros do mosquito.

A malária é uma doença causada por um parasita Plasmodium, transmitido pela picada de mosquitos infectados. No Brasil, a malária é frequente na região amazônica, propaga-se por animais ou insetos; a prevenção também ocorre com controle do mosquito por meio do uso de inseticidas e/ou eliminação de água parada, que pode ser ponto de reprodução.

Também foi verificada a porcentagem expressiva de 20,5\% de pessoas que contraíram a COVID-19, sendo esta uma doença causada pelo coronavírus, denominado SARS-CoV-2; apresenta infecções assintomáticas a quadros graves. Segundo a Organização Mundial de Saúde, cerca de 80\% dos pacientes podem ser assintomáticos ou poucos sintomas.

Nesse cenário de pandemia, o acesso aos serviços de saneamento básico tem se tornado aliado no combate a essa doença, pois dentre as principais medidas de prevenção está a lavagem das mãos com frequência, além de fazer uso de álcool em gel e praticar o distanciamento social. Porém, o que é básico não está ao alcance de todos os moradores, principalmente, nas periferias das cidades brasileiras.

Todavia, foi observado que, felizmente, nenhum dos entrevistados foi acometido com enfermidades do tipo Febre Amarela (causada por um arbovírus) e Leishmaniose (causada por um protozoário do gênero leishmania). Ademais, houve percentual considerável de 79,5\% das pessoas que não contraíram nenhuma das enfermidades indicadas.

De acordo com estudos realizados pela Associação Brasileira de Engenharia Sanitária e Ambiental (ABES) (2020), o Brasil registrou 40 mil internações por falta de saneamento nos primeiros meses de 2020 e os gastos chegaram a R 16 milhões 
aos cofres públicos. Desse valor total, quase metade foi empregada na região Norte. Tradicionalmente, essa região apresenta graves falhas e os piores índices de saneamento básico do Brasil.

\subsection{Fonte de água utilizada para abastecimento na residência}

$\mathrm{O}$ acesso adequado à água tem se tornado imprescindível, sobretudo em tempos de pandemia, independente da alternativa utilizada. Buss (2020) e Mallapaty (2020) salientam que a gestão adequada e segura do acesso aos serviços de água oferecem diversos outros benefícios em favor do controle das transmissões de doenças.

No que se refere às fontes alternativas ou não de abastecimento de água utilizadas para abastecimento dos domicílios em CDA, foi observado que $28,2 \%$ dos entrevistados possuíam meios à rede pública de abastecimento de água como fonte principal. Na cidade de CDA, tal serviço é de responsabilidade da prestadora Companhia de Saneamento do Pará (COSANPA), a qual também é responsável pela expansão desse serviço em todo o território paraense.

O poço (artesiano ou semiartesiano) também era alternativa de abastecimento de água em $75 \%$ das residências em Conceição do Araguaia, segundo respostas dos entrevistados. No que diz respeito a outras fontes alternativas, o uso de poço (furado na terra) era utilizado por 7,1\% dos domicílios e 1,3\% realizavam o abastecimento em suas residências com água do rio.

Ademais, $0,6 \%$ dos entrevistados não souberam informar as fontes alternativas ou não de água utilizada para abastecimento de seus domicílios. Além disso, foi observado, também, que nenhuma das residências fazia utilização das alternativas de cisterna (coletora de água das chuvas) e córrego para abastecimento.

\subsection{Frequência de ocorrência de falta de água na residência}

Um dos pontos abordados no formulário virtual reporta-se à frequência da falta de água nas residências. Neste sentido, foi verificado que 72,4\% dos entrevistados indicaram que não ocorria falta de água, ou seja, o abastecimento de água nesses domicílios acontecia de forma contínua, sem interrupções, o que é um ponto positivo, principalmente em tempos de pandemia, quando o acesso a esse serviço tem se tornado tão essencial.

Todavia, foi notado que em 13,5\% dos domicílios havia falta de água pelo menos uma vez por semana, segundo as informações dos entrevistados. Tal situação deve aumentar a vulnerabilidade das pessoas que não dispõem do acesso à água potável de modo ininterrupto, particularmente no momento de pandemia do coronavírus no Brasil.

De acordo com a PNAD (2020), lavar as mãos com frequência é uma das formas de prevenção contra o COVID-19. Porém, se o domicílio se encontra sem água, como realizar a higienização? Infelizmente essa é a realidade de mais de $10 \%$ dos domicílios brasileiros, conforme destacado pela PNAD (2020). Além disso, a pesquisa ressalta que nos domicílios pesquisados também ocorreu a falta água, por pelo menos uma vez por semana.

O acesso à água potável é declarado pela ONU como direito fundamental e instrumento para promoção da saúde, especialmente às populações mais vulneráveis. Ademais, é o $6^{\circ}$ objetivo da ONU para o desenvolvimento sustentável. Até 2030, a ONU enfatiza a importância de alcançar o acesso universal e equitativo à água potável e segura para todos.

Segundo o estudo da ABES (2020), em 2020 as internações por doenças causadas pela ausência de saneamento ocuparam, em média, 4,2\% dos leitos do SUS, por cerca de três dias. A pesquisa destaca, ainda, que as ocupações ocorreram durante a pandemia do coronavírus e podem ser evitadas com mais investimentos em serviços de abastecimento de águas e esgotamento sanitário.

Em tempos de pandemia, é sabido e constato por diversas pesquisas que as práticas básicas de higienização têm impacto significativo no combate ao coronavírus. Todavia, a UNICEF (2020) ratifica que o cenário mundial é assustador, uma 
vez que, lamentavelmente, 3 bilhões de pessoas não possuem lavatórios com água e sabão em casa; isto representa cerca de $40 \%$ da população mundial.

\subsection{Existência de ligação do domicílio à rede coletora de esgoto}

Na pesquisa, também foi questionada a existência de rede coletora de esgoto em CDA e se os domicílios estavam ligados. Diante disso, foi observado que 73,7\% não tinha alcance à rede coletora de esgoto. Sobre isso, no relatório do SNIS (2020) pode ser constatado que apenas $54,1 \%$ dos brasileiros têm acesso à coleta de esgoto. Além do mais, quase 100 milhões de brasileiros não têm meios a esse serviço.

Diversas universidades têm desenvolvido pesquisas com o intuito de contribuir para o controle do Covid-19. No Brasil, em estudos realizados pela UFMG e Instituto Nacional de Ciência e Tecnologia em Estações Sustentáveis de Tratamento de Esgoto mostraram a presença do coronavírus nos esgotos.

Por outro lado, é possível constatar que apenas 5,8\% dos domicílios informaram estarem ligados à rede coletora de esgoto, encontrando-se muito aquém da média nacional, que era de 54,1\%, conforme diagnósticos do SNIS (2020). Ao finalizar, foi verificado que $20,5 \%$ dos entrevistados não souberam informar a condição do domicílio, se estavam ligados à rede coletora de esgoto ou não.

\subsection{Conhecimento da destinação do esgoto gerado na residência}

Por fim, foi perguntado aos moradores de CDA qual o destino do esgoto (águas servidas) gerado em seus domicílios. Nesse contexto, em 32,7\% das residências o esgoto gerado é destinado ao sistema de fossa séptica (revestida impermeabilizada); tal sistema é tecnicamente recomendado também em casos de ausência de rede coletora de esgoto, desde que seja projetado em conformidade com as normas NBR 7.229 (1992) e NBR 13.969 (1997).

Todavia, 24,4\% dos domicílios utilizavam fossa negra para disposição do esgoto gerado. Tal alternativa não é um sistema com estrutura simplificada suficiente para tratamento do efluente, já que construções irregulares e o uso das fossas negras podem ocasionar riscos ao meio ambiente, contaminando o solo e os recursos hídricos, além de poder causar diversas doenças. Ademais, 28,2\% dos entrevistados não souberam informar o destino do esgoto gerado em seus domicílios.

Segundo Gomes (2019), ao se tratar de endemias, uma parcela considerável delas tem sua disseminação devida à falta de água e esgoto tratados. A ausência dos serviços de tratamento de esgoto pode contribuir para a proliferação de inúmeras doenças. Neste sentido, a disposição adequada dos esgotos é essencial para a proteção da saúde pública e proteção do meio ambiente.

Assim, no diagnóstico realizado pelo SNIS (2020), é possível verificar que apenas 54,1\% dos brasileiros têm acesso à coleta de esgoto; e de todo esgoto gerado no país, apenas 49,1\% são tratados. Na região Norte, o cenário é ainda mais grave, lamentavelmente, apenas $12,3 \%$ (média nacional $54,1 \%$ ) da população é atendida com serviços de esgotamento sanitário.

\section{Considerações Finais}

Em tempos de pandemia, ficou evidenciado ainda mais a importância do saneamento básico no combate às doenças infecciosas, dentre elas a COVID-19. Neste sentido, assegurar o acesso da população a esses serviços é também garantir qualidade de vida e propiciar cuidados essenciais de higiene, principalmente em comunidades mais vulneráveis.

Com a pesquisa realizada, foi possível perceber que os objetivos propostos foram alcançados. O estudo constatou que apesar de ser um direito assegurado pela lei n 14.026 (2020), nem todos os moradores de CDA tinham acesso aos serviços de abastecimento de água e esgotamento sanitário de forma adequada, assim como grande parte da população brasileira. 
Foi observado que $75 \%$ das residências utilizavam alternativa de poço (artesiano ou semiartesiano) para abastecimento de água. Ademias, em 13,5\% dos domicílios ocorria a ausência de água ao menos uma vez por semana. Foi constatado, também, que 73,7\% das residências não tinham acesso à rede coletora de esgoto; e em 24,4\% utilizavam fossa negra para disposição do esgoto gerado.

Diante do cenário pesquisado e observado, é reiterada a extrema relevância e necessidade de maior planejamento e investimentos em estruturas de saneamento básico, tanto nas capitais quanto nos municípios localizados no interior do Estado do Pará. Entende-se que, dessa forma, será possível reduzir não só o contágio da COVID-19, mas também de tantas outras doenças relacionadas à falta desse serviço essencial.

A realidade analisada na cidade de Conceição do Araguaia é uma amostra de tantos outros municípios do Pará, na Amazônia, onde povoamento se forma, muitas vezes, sem planejamento e estruturas de saneamento. Portanto, nota-se a necessidade de ações de planejamento e implementação de estruturas básicas de saneamento, as quais possam proporcionar dignidade e qualidade de vida aos moradores desses municípios.

\section{Referências}

ABES. (2020). Saneamento X Saúde. Associação Brasileira de Engenharia Sanitária e Ambiental - ABES. Vitória, ES. https://abes-es.org.br/brasil-registra-40mil-internacoes-por-falta-de-saneamento-nos-primeiros-tres-meses-do-ano-gastos-chegam-a-r-16-milhoes/.

Alves, E. M. (2018). Trajetória das decisões sobre políticas públicas de esgotamento sanitário e as influências das coalizões de defesa: Estudo de caso de Ubatuba - SP. Programa de pós-graduação em Ciência Ambiental, Instituto de Energia e Ambiente, Universidade de São Paulo.

Associação Brasileira de Normas Técnicas. (1993). NBR: 7229: Projeto, construção e operação de sistema de tanque séptico.

Associação Brasileira de Normas Técnicas. (1997). NBR: 13.969: Tanque sépticos-unidade de tratamento complementar e disposição final dos efluentes líquidos- Projeto, construção e operação. Rio de Janeiro, ano: 1997.

Brasil. (2019). Ministério das Cidades. Sistema Nacional de Informações sobre Saneamento. http://snis.gov.br/diagnostico-agua-e-esgotos

Brasil. (2020). lei n 14.026 , de 15 de julho de 2020. Atualiza o marco legal do saneamento básico e altera a lei n 9.984 , de 17 de julho de 2000 . Brasília, DF, 2020. http://www.planalto.gov.br/ccivil_03/_ato2019-2022/2020/lei/114026.htm

Brasil. (2020). Ministério do Desenvolvimento Regional. Secretaria Nacional de Saneamento - SNS. Sistema Nacional de Informações sobre Saneamento: $25^{\circ}$ Diagnóstico dos Serviços de Água e Esgotos - 2019. SNS/MDR. 183 p.: il.

Brasil. (2021). Instituto Brasileiro de Geografia e Estatística: Pesquisa Nacional por Amostra de Domicílios Contínua - PNAD. https://www.ibge.gov.br/estatisticas/multidominio/condicoes-de-vida-desigualdade-e-pobreza/17270-pnad-continua.html?=\&t=o-que-e

Buss, P.m. (2020). De pandemias, desenvolvimento e multilateralismo [base de dados na online]. Le Monde Diplomatique.

Chernicharo, C. A. L. (2018). Panorama do tratamento de esgoto sanitário nas regiões Sul, Sudeste e Centro-Oeste do Brasil: tecnologias mais empregadas. Revista DAE, 66 (213), 5-19.

Estrela, C. (2018). Metodologia Científica: Ciência, Ensino, Pesquisa. Editora Artes Médicas.

Habitat Brasil. (2020). Observatório das Metrópoles subscreve representação junto ao MPF para proteção contra o coronavírus de favelas, periferias e grupos vulneráveis [base de dados online]. São Paulo: Observatório das Metrópoles.

Instituto Trata Brasil: Painel Sanemaneto Brasil. (2021). http://www.tratabrasil.org.br/saneamento/principais-estatisticas/no-mundo/esgoto

Mallapaty S. (2020). How sewage could reveal true scale of coronavirus outbreak. Nature; 580 (7802), 176-177.

Organização Das Nações Unidas-ONU. (2010). https://brasil.un.org/pt-br/55564-agua-potavel-direito-humano-fundamental

Organização Mundial da Saúde (OMS). (2020). Abastecimento de água, esgotamento sanitário, higiene e manejo de resíduos com o vírus da COVID-19 Orientação provisória [base de dados online]. OMS.

Périssé, A. (2020). Covid-19 e vulnerabilidades: considerações sobre proteção social nas favelas. Nota técnica [base de dados online]. Rio de Janeiro: Comitê Fiocruz COVID-19 nas Favelas - Fundação Oswaldo Cruz.

Schwemlein, S.; Cronk, R.; \& Bartram, J. (2016). Indicators for monitoring water, sanitation, and hygiene: a systematic review of indicator selection methods. International Journal of Environmental Research and Public Health. 13 (333), 1-15.

Wan, Y., Shang, J., Graham, R., Baric, R. S. \& Li, F. (2020). Receptor recognition by novel coronavirus from Wuhan: an analysis based on decade-long structural studies of SARS. Journal Virology, 94. 
Research, Society and Development, v. 10, n. 8, e40510817507, 2021

(CC BY 4.0) | ISSN 2525-3409 | DOI: http://dx.doi.org/10.33448/rsd-v10i8.17507

Wang D., Hu B., Hu C., Zhu F., Liu X. \& Zhang J. (2020). Clinical characteristics of 138 hospitalized patients with 2019 novel coronavirus-infected pneumonia in Wuhan, China. JAMA. 10.1001/jama.2020.1585

Wu, F., Xiao, A. \& Zhang, J. (2020). SARS-CoV-2 titers in wastewater are higher than expected from clinically confirmed cases. MedRxiv And Biorxiv, [S. 1.], p. $1-14$.

Xiao, F. (2020). Evidence for gastrointestinal infection of SARS-CoV-2. Gastroenterology, 158, 1831-1833.

Yinyin, Y. E., Robert, M., Graham, K. E. \& Wigginton, K. R. (2016). Survivability, partitioning, and recovery of enveloped viruses in untreated municipal wastewater. Environmental Science \& Technology, 50(10), 5077-5085.

Zhang, C. M. et al. (2016). Elimination of viruses from domestic wastewater: requirements and technologies. World Journal of Microbiology and Biotechnology. 32(4), 1-9.

Zhu N., Zhang D., Wang W., Xingwang Li., Yang B. \& Song J. (2019). A novel Coronavirus from patients with pneumonia in China. N Eng J Med 2020; 1-7. 10.1056/NEJMoa2001017 